\title{
Construction of a novel MK-4 biosynthetic pathway in Pichia pastoris through heterologous expression of HsUBIAD1
}

\author{
Xiaowen Sun 1,2, Hui Liu', Peng Wang ${ }^{1}$, Li wang ${ }^{1}$, Wenfeng Ni 1,2, Qiang Yang 1,2, Han Wang 1,2, Hengfang Tang ${ }^{1,2}$, \\ Genhai Zhao ${ }^{1 *}$ and Zhiming Zheng ${ }^{1 *}$ (D)
}

\begin{abstract}
Background: With a variety of physiological and pharmacological functions, menaquinone is an essential prenylated product that can be endogenously converted from phylloquinone $\left(\mathrm{VK}_{1}\right)$ or menadione $\left(\mathrm{VK}_{3}\right)$ via the expression of Homo sapiens UBIAD1 (HsUBIAD1). The methylotrophic yeast, Pichia pastoris, is an attractive expression system that has been successfully applied to the efficient expression of heterologous proteins. However, the menaquinone biosynthetic pathway has not been discovered in P. pastoris.

Results: Firstly, we constructed a novel synthetic pathway in P. pastoris for the production of menaquinone-4 (MK4) via heterologous expression of HsUBIAD1. Then, the glyceraldehyde-3-phosphate dehydrogenase constitutive promoter $\left(\mathrm{P}_{G A P}\right)$ appeared to be mostsuitable for the expression of HsUBIAD1 for various reasons. By optimizing the expression conditions of $\mathrm{Hs}_{\mathrm{S}} \mathrm{B} I \mathrm{AD} 1$, its yield increased by 4.37 times after incubation at $\mathrm{pH} 7.0$ and $24^{\circ} \mathrm{C}$ for $36 \mathrm{~h}$, when compared with that under the initial conditions. We found HsUBIAD1 expressed in recombinant GGU-23 has the ability to catalyze the biosynthesis of MK-4 when using $\mathrm{VK}_{1}$ and $\mathrm{VK}_{3}$ as the isopentenyl acceptor. In addition, we constructed a ribosomal DNA (rDNA)-mediated multi-copy expression vector for the fusion expression of SaGGPPS and PpIDI, and the recombinant GGU-GrlG afforded higher MK-4 production, so that it was selected as the high-yield strain. Finally, the yield of MK-4 was maximized at $0.24 \mathrm{mg} / \mathrm{g}$ DCW by improving the GGPP supply when $\mathrm{VK}_{3}$ was the isopentenyl acceptor.
\end{abstract}

Conclusions: In this study, we constructed a novel synthetic pathway in P. pastoris for the biosynthesis of the high value-added prenylated product MK-4 through heterologous expression of HSUBIAD1 and strengthened accumulation of GGPP. This approach could be further developed and accomplished for the biosynthesis of other prenylated products, which has great significance for theoretical research and industrial application.

Keywords: Pichia pastoris, Aromatic prenyltransferase, HsUBIAD1, Geranylgeranyl diphosphate synthase, Menaquinone

\section{Background}

Predominant Most research on vitamin $\mathrm{K}$ has been devoted to its physiological function as an essential cofactor for $\gamma$-glutamyl carboxylase (GGCX), an enzyme

\footnotetext{
*Correspondence: zhgh327@ipp.ac.cn; zhengzhiming2014@163.com ${ }^{1}$ Key Laboratory of High Magnetic Field and lon Beam Physical Biology, Hefei Institutes of Physical Science, Chinese Academy of Sciences, Hefei 230031, Anhui, People's Republic of China

Full list of author information is available at the end of the article
}

that catalyzes the posttranslational modification of proteins involved in blood coagulation and bone metabolism and prevention of cardiovascular calcification [1-5]. Natural vitamin $\mathrm{K}$ has two molecular forms: the plant form, phylloquinone (PK) or vitamin $\mathrm{K}_{1}$, and the bacterial form, known as the menaquinones (MKs) or vitamin $K_{2}[6,7]$. The common structure of a 2-methyl-1,4-naphthoquinone nucleus is present in both PK and MKs, which are structurally different in the length and degree of saturation of the isoprene side-chain. At the 3-position of the 
common nucleus, PK has a monounsaturated side chain of four isoprenyl residues. In contrast, MKs are classified into 14 types, which are named MK-n according to the number of repeating unsaturated isoprenyl units. Over the past few years, numerous studies have indicated that MKs can play a role in treating mitochondrial pathologies such as Parkinson's disease and amyotrophic lateral sclerosis, and even exhibit anticancer activity in several types of cancer cells, including liver cancer, lung cancer, bladder cancer, prostate cancer and ovarian cancer [8-11]. PK is primarily obtained from leafy green vegetables and is endogenously converted to menatetrenone (MK-4) by cleavage of the side chain in the intestine, then menadione $\left(\mathrm{VK}_{3}\right)$ is delivered through the mesenteric lymphatic system and blood circulation to tissues such as the brain, kidney and pancreas $[1,4,12]$. Recent research has found that Homo sapiens UbiA prenyltransferase containing 1 (HsUBIAD1), a human homologue of Escherichia coli prenyltransferase menA and mammalian mitochondrial prenyltransferase $\mathrm{COQ}_{2}$ catalyzes the conversion of PK to its prenylated derivative MK-4 [1214]. As a member of the membrane prenyltransferase family, the structure of $H s \mathrm{UBIAD} 1$ has been resolved in many studies; it contains eight transmembrane helices and two characteristic conserved motifs (NDxxDxxxD and DxxxD) $[15,16]$. In particular, the isoprenyl substrate is located in the membrane embedded active site between the two aspartate-rich motifs. In previous studies, $H s$ UBIAD1 was usually expressed in animal cell expression systems to investigate its related properties [6, 17]. This may be because animal cell expression systems have certain advantages in expressing desired proteins with near-native functional properties. Nevertheless, we cannot ignore the shortcomings of low expression levels, high cost and time- consuming and complicated culture conditions. The components of the medium used for animal cell culture are relatively complex and expensive. In addition, animal cell culture systems are sensitive to the environment and often present the risk of infection with bacteria, fungi and viruses, resulting in relatively high requirements for the operating environment and equipment. Furthermore, it is relatively difficult to screen stable high expression strains using animal cell expression systems and often requires a longer time period due to their low recombination rate. The methylotrophic yeast, Pichia pastoris has become an attractive workhorse for biotechnology, especially for the production of both secreted and intracellular heterologous proteins [18-21]. It is an important heterologous protein expressing system that has several advantages over other eukaryotic and prokaryotic expression systems. Firstly, P. pastoris not only has the ability to grow high cell densities with a rapid growth rate, it is also capable of metabolizing methanol as its sole carbon and energy source [22, 23]. In addition, the heterologous genes of interest have been stably integrated into the genome, ideally into a targeted locus via homologous recombination that eliminates segregational instability, which is different from expression via plasmid DNA $[24,25]$. Also, P. pastoris has the subcellular structure of eukaryotes, so that it exhibits certain advantages in post-translational modifications, including polypeptide folding, phosphorylation, glycosylation and methylation [26, 27]. In order to achieve successful recombinant protein expression, choosing the appropriate expression vector is an important prerequisite as well as selection of the host strain. Thus far, the majority of heterologous proteins have been successfully expressed by methanol inducible alcohol oxidase promoter $\left(\mathrm{P}_{A O X 1}\right)$ and glyceraldehyde-3-phosphate dehydrogenase constitutive promoter $\left(\mathrm{P}_{G A P}\right)$. In the presence of methanol, $\mathrm{P}_{A O X 1}$ is induced to generate the enzyme alcohol oxidase [28], which catalyzes the first step of formaldehyde assimilation pathways, converting methanol to formaldehyde [29, 30]. It has been reported that the expression levels of heterologous proteins are tightly regulated by $\mathrm{P}_{A O X 1}[31,32]$. However, large amounts of methanol are needed as inducer for large-scale fermentations, resulting in risks of toxicity and safety. From a security perspective, the constitutive expression vector controlled by $\mathrm{P}_{G A P}$ is more appropriate for recombinant protein production. Furthermore, recent studies have shown that the level of expression seen with the $\mathrm{P}_{G A P}$ can be slightly higher than that obtained with the $\mathrm{P}_{A O X 1}[29,31,33,34]$.

Geranylgeranyl diphosphate (GGPP), an important precursor for the biosynthesis of MK-4, consists of isoprenoid building blocks accumulated via the mevalonate (MVA) pathway in P. pastoris (Fig. 1). Research has shown that the geranylgeranyl diphosphate synthase from the archaebacterium Sulfolobus acidocaldarius (SaGGPPS) is capable of synthesizing geranylgeranyl diphosphate through sequential condensations of isopentenyl diphosphate (IPP) with dimethylallyl diphosphate (DMAPP), thereby reducing competition for the common precursor farnesyl diphosphate (FPP) [35-37].

A previous study [38] found that P. pastoris has much higher menadione and MKs tolerance when compared with other host strains such as E. coli. As an appropriate host due to its superior ability to express eukaryotic proteins, $P$. pastoris has many biotechnological applications; however, the menaquinone biosynthetic pathway has not been discovered in P. pastoris. Considering all of the above, in the present study we have attempted to construct a novel synthetic pathway in $P$. pastoris for the production of MK-4 by heterologous expression of $H s \mathrm{UBIAD} 1$. Meanwhile, to increase MK-4 production, the Sulfolobus acidocaldarius geranylgeranyl diphosphate 
<smiles>CC1=C(C/C=C(\C)CCCC(C)[AlH2])C(=O)c2ccccc2C1=O</smiles>

$\mathrm{VK}_{1}$<smiles>CC1=CC(=O)c2ccccc2C1=O</smiles>

$\mathrm{VK}_{3}$

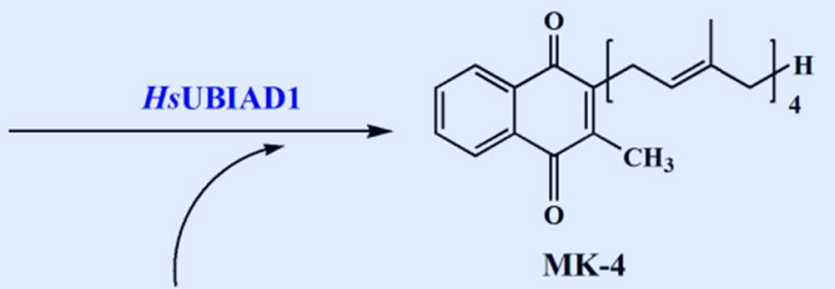<smiles>O=C[C@H](O)[C@H](O)[C@H](O)[C@H](O)CO</smiles>

Glucose<smiles>O=C(O)COC(=O)C[C@@](I)(CC(=O)O)CC(O)O</smiles><smiles>CC(C)=CCC/C=C(/C)CC/C=C(\C)CCC/C(C)=C/COP</smiles>

GGPP

GGPPS

$-\mathrm{OH}$<smiles>CC(C)=CCC/C(C)=C/CC/C(C)=C/COc1ccccc1</smiles>

FPP

HO

Mevalonate-PP<smiles>CCC=C(C)CCOc1ccccc1</smiles>

$\uparrow$

FPPS<smiles>CC(C)=CCO[OH2+]</smiles>

GPP

SaGGPPS

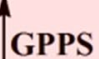

IDI

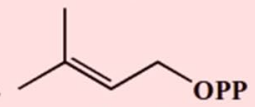

DMAPP

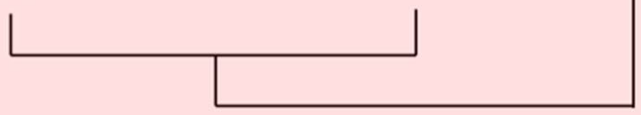

Fig. 1 Biosynthetic pathway for MK-4 in P. pastoris GS115

synthase ( $\mathrm{SaGGPPS}$ ) was introduced into $P$. pastoris to improve GGPP supply, although P. pastoris does contain the genes that encode a GGPP synthase.

\section{Materials and methods}

\section{Strains and plasmids}

Escherichia coli DH5 $\alpha$ cells used for plasmid propagation were preserved in our laboratory. P. pastoris GS115 (kindly provided by the Laboratory of Signaling Transduction and Transcription, University of Science and Technology of China, Hefei, China) was used to construct the MK-4 production strain. Expression vectors
pPICZA and pGAPZA were purchased from YouBio (Hunan, China). All strains and plasmids used in this study are listed in Additional file 1: Tables S1 and S2.

\section{Culture conditions}

Escherichia coli were incubated at $37^{\circ} \mathrm{C}$ in a low-salt LB medium consisting of $1 \%$ tryptone, $0.5 \%$ yeast extract, and $0.5 \% \mathrm{NaCl}$. YPD medium ( $2 \%$ tryptone, $1 \%$ yeast extract, and $2 \%$ glucose) was used for cultivating $P$. pastoris for further preparation of competent cells. BMGY medium used for activating recombinant $P$. pastoris consisted of $2 \%$ tryptone, $1 \%$ yeast extract, $1.34 \%$ yeast 
nitrogen base (YNB) medium without amino acids, $1 \%$ glycerol, $4 \times 10^{-5} \%$ biotin, and $0.1 \mathrm{M}$ potassium phosphate ( $\mathrm{pH}$ 6.0). The constitutive recombinant $P$. pastoris with $\mathrm{P}_{G A P}$ promoter was incubated for approximately $24 \mathrm{~h}$ at $30{ }^{\circ} \mathrm{C}$ and $250 \mathrm{rpm}$ in $250-\mathrm{mL}$ flasks containing $25 \mathrm{~mL}$ of BMGY medium. For protein expression driven by $\mathrm{P}_{A O X 1}$ in P. pastoris, the cells were harvested by centrifuging at $5000 \times g$ for $10 \mathrm{~min}$ at room temperature and resuspended in BMMY medium (2\% tryptone, $1 \%$ yeast extract, $1.34 \% \mathrm{YNB}, 4 \times 10^{-5} \%$ biotin and $0.1 \mathrm{M}$ potassium phosphate ( $\mathrm{pH}$ 6.0) and $0.3 \%$ methanol) to a final density at $\mathrm{OD}_{600}$ of 1.0, and methanol was added to the BMMY medium to a final concentration of $0.3 \%$ every $24 \mathrm{~h}$. Solid medium was obtained by adding $2 \%$ agar to the liquid medium. The media were prepared by sterilization at $121{ }^{\circ} \mathrm{C}$ for $20 \mathrm{~min}$, and glucose solution was sterilized separately at $115^{\circ} \mathrm{C}$ for $15 \mathrm{~min}$. In addition, the stock solution of $10 \times \mathrm{YNB}$ and $500 \times$ biotin were added separately after filtration sterilization.

\section{Bioinformatics analysis of HsUBIAD1}

SOPMA (https://npsa-prabi.ibcp.fr/cgi-bin/npsa_autom at.pl?page $=$ npsa_sopma.html) was applied to predict the secondary structure of $H s$ UBIAD1 from the amino acid sequence, in particular to predict the rate of secondary structural elements [39]. Since the hydrophobicity of an amino acid sequence predicts the protein folding, we analyzed the hydrophobicity of $H s$ UBIAD1 using several tools including SOSUI, ProtScale and DNAMAN. SignalP 3.0 (http://www.cbs.dtu.dk/services/SignalP-3.0/) is commonly used to predict the presence and location of signal peptide, and it was used to discriminate the signal peptide of HsUBIAD1 [40]. WoLF PSORT (https ://wolfpsort.hgc.jp/) was used to predict the subcellular location of $H s$ UBIAD1 based on the PSORT II program [41]. The transmembrane topology of HsUBIAD1 was predicted using a range of transmembrane topology predictors, such as Phobius, OCTOPUS and TMHMM. And the online analysis software, Protter, was used to visualize the transmembrane topology of HsUBIAD1. SWISS-MODEL, an automated protein homology-modelling server, was used to predict the tertiary structure of $H s$ UBIAD1 based on its amino acid sequence.

The homologous sequences of HsUBIAD1 obtained from the National Center for Biotechnology Information (NCBI) database were aligned using Clustal X. Then, phylogenetic analyses were conducted using MEGA X program. The evolutionary history was inferred using the neighbor-joining method based on the Poisson model and bootstrap analysis was carried out with 1000 replicates. The phylogenetic tree was further edited by EvolView. Multiple sequence alignment of $A p \mathrm{UbiA}$, AtPPT1, EcUbiA, LePGT-1, OsPPT, $S c \mathrm{CoQ}_{2}, B l \mathrm{MenA}$,
EcMenA, KpMenA, PaUBIAD1, PtUBIAD1 and $H s$ UBIAD1 were performed using Clustal $\mathrm{X}$ and then analyzed by ESPript 3.0.

\section{Construction of the expression vector}

The codon of the HsUBIAD1 gene, which was artificially synthesized by General Biosystems, Inc. (Anhui, China), was optimized based on codon preference to achieve high levels of protein expression in P. pastoris. The CAI and GC contents of the optimized sequence were analyzed by the GenScript Web server (http://www.gensc ript.com). The $H s$ UBIAD1 gene was amplified using primers UBIAD1-F-EcoRI and UBIAD1-R-NotI listed in Additional file 1: Table S3, which contained full-length UBIAD1. The PCR products were digested with EcoRI and NotI and inserted between the EcoRI and NotI sites of pGAPZA where $H s$ UBIAD1 is under the control of constitutive promoter $\mathrm{P}_{G A P}$ on the vector, and the resulting plasmid was named pGU. The $H s$ UBIAD1 fragment described above was cloned into multiple cloning sites of pPICZA, which thus generated pPU. In the recombinant $\mathrm{pPU}$ vector, $H s \mathrm{UBIAD} 1$ protein was controlled by $\mathrm{P}_{A O X 1}$. The recombinant plasmids grown on low-salt LB agar plates with $50 \mu \mathrm{g} / \mathrm{mL}$ Zeocin were sequenced after colony PCR to confirm the presence and orientation of the insert.

To obtain stable multi-copy integrants in P. pastoris, we attempted to construct a multi-copy expression vector by integrating the nucleotide sequence of a portion of the $28 \mathrm{~S}$ ribosome DNA (rDNA) amplified from P. pastoris into the expression vector pGAPZA. Concretely, the rDNA fragment was amplified from the genomic DNA of $P$. pastoris GS115 using primers rDNA-F and rDNA-R listed in Additional file 1: Table S3, and cloned into the BamHI site of pGAPZA to gain the desired expression vector pGAPZA-rDNA. The geranylgeranyl pyrophosphate synthase gene (ggpps) from Sulfolobus acidocaldarius used in this study was artificially synthesized by General Biosystems, Inc. (Anhui, China). The coding region of ggpps was amplified by PCR using primers GGPPS-F-EcoRI and GGPPS-R-NotI listed in Additional file 1: Table S3, and cloned into the expression vector pGAPZA-rDNA using the same methods, thus generating $\mathrm{pGrG}$. Subsequently, the expression cassettes of $S a$ GGPPS were integrated into the rDNA locus by homologous recombination.

The IPP isomerase gene (idi) was PCR amplified from the genomic DNA of $P$. pastoris GS115 using primers IDI-F-EcoRI and IDI-R (Additional file 1: Table S3), while the ggpps fragment was PCR amplified from the plasmid pGrG by primers GGPPS-F and GGPPS-R-NotI listed in Additional file 1: Table S3. The idi-ggpps fusion gene was constructed by fusing the ggpps gene to the 3 -end of 
the $i d i$ gene as follows, and the flexible linker (GGGGS) sequence GGTGGCGGTGGCTCGGGCGGTGGT GGGTCG was inserted between the idi and ggpps genes. These two fragments were purified separately and then fused by overlap extension PCR using the primer pair of IDI-F-EcoRI and GGPPS-R-NotI (Additional file 1: Table S3), which contained EcoRI at the $5^{\prime}$-end and NotI at the $3^{\prime}$-end. The idi-ggpps fusion gene was digested with EcoRI and NotI and cloned into multicloning sites of pGAPZA-rDNA as described earlier, and the corresponding plasmid of pGrIG was then constructed.

\section{Transformation and screening of recombinant HsUBIAD1-producing P. pastoris}

The electrocompetent cells of P. pastoris GS115 were prepared according to the following protocol. The single colony of $P$. pastoris was grown in $250-\mathrm{mL}$ flasks containing $25 \mathrm{~mL}$ of YPD medium and incubated at $30{ }^{\circ} \mathrm{C}$ and $250 \mathrm{rpm}$ overnight (16-18 h). $50 \mathrm{~mL}$ of fresh YPD medium were inoculated in a $250-\mathrm{mL}$ flask with $0.5 \mathrm{~mL}$ of the overnight culture until it reached an $\mathrm{OD}_{600}$ of 1.11.3. The culture was centrifuged at $1500 \times g$ for $5 \mathrm{~min}$ at $4{ }^{\circ} \mathrm{C}$, then the cells were suspended in $20 \mathrm{~mL}$ of ice-cold, sterile water. The cells were centrifuged at $1500 \times \mathrm{g}$ for $5 \mathrm{~min}$ at $0{ }^{\circ} \mathrm{C}$, then resuspended the pellet with $20 \mathrm{~mL}$ of ice-cold sterile water, repeatedly. After three centrifugations, the pellet was resuspend in $5 \mathrm{~mL}$ of ice-cold $1 \mathrm{M}$ sorbitol. After centrifugation again at $1500 \times g$ for $5 \mathrm{~min}$ at $0{ }^{\circ} \mathrm{C}$, the cells were finally suspended in $0.2 \mathrm{~mL}$ of icecold $1 \mathrm{M}$ sorbitol.

The recombinant vectors pGU and pPU were linearized by the restriction enzymes $B s p \mathrm{HI}$ and SacI separately, then electroporated into the disarmed P. pastoris GS115 by electroporation. Transformants were selected on MD histidine deficient plates $\left(1.34 \% \mathrm{YNB}, 4 \times 10^{-5} \%\right.$ biotin, $2 \%$ glucose, and $2 \%$ agar) containing Zeocin $(100 \mu \mathrm{g} /$ $\mathrm{mL}$ ), and the presence the of expression cassette was confirmed by colony PCR using pGAP-F/3'AOX1 and 5'AOX1/3'AOX1 primer pairs listed in Additional file 1: Table S3. After initial selection, a range of concentrations $(200,400,500,1000 \mu \mathrm{g} / \mathrm{mL})$ of Zeocin was used to select multi-copy transformants.

\section{Expression of the recombinant HsUBIAD1}

The colony that was positive for GGU and GPU was cultured for $24 \mathrm{~h}$ at $30^{\circ} \mathrm{C}$ and $250 \mathrm{rpm}$ in an $18 \times 180 \mathrm{~mm}$ test tube containing $5 \mathrm{~mL}$ of BMGY medium for the expression of recombinant $H s$ UBIAD1. After $24 \mathrm{~h}$ of cultivation, activated GPU cells were harvested and resuspended in $5 \mathrm{~mL}$ of BMMY medium in the same test tube for inductive fermentation at $22^{\circ} \mathrm{C}$ for $48 \mathrm{~h}$ with the addition $2 \%$ methanol every $24 \mathrm{~h}$. The intracellular proteins of recombinant $P$. pastoris were extracted using Yeast
Total Protein Extraction Kit (Sangon Biotech, Shanghai, China). Then, the expression levels of recombinant $H s$ UBIAD1 were detected by dot-blot to screen the highyield $H s$ UBIAD1-producing strains.

To obtain the optimal expression conditions in P. pastoris GS115, the culture temperature ranged from 20 to $30{ }^{\circ} \mathrm{C}$, and the initial $\mathrm{pH}$ values ranged from 4 to 9 . The recombinant $P$. pastoris was grown at $250 \mathrm{rpm}$ in $250-\mathrm{mL}$ flasks containing $50 \mathrm{~mL}$ of BMGY medium, and samples were taken every $12 \mathrm{~h}$ during the fermentation. Once the culture was completed, the samples were centrifuged at $13,000 \times g$ for $5 \mathrm{~min}$ at $4{ }^{\circ} \mathrm{C}$, then the recombinant $H s$ UBIAD1 was extracted from the wet cell mass using the Yeast Total Protein Extraction Kit. Next, the expression levels were determined by western blot analysis, and ImageJ was used to process and analyze the results with $\beta$-actin as the reference. At the same time, another portion of the wet cells after centrifugation was dried in a vacuum freeze dryer for $6-8 \mathrm{~h}$, and the biomass of the recombinant GGU-23 was detected by measuring the dry cell weight $(\mathrm{DCW})$. All values reported are the averages of triplicate trials ( \pm standard error).

\section{Western blot detection of HsUBIAD1}

The samples were mixed with $5 \times$ SDS-PAGE sample loading buffer and boiled for $5 \mathrm{~min}$. Protein bands were separated by SDS-PAGE with a $12 \%$ separating gel and a $5 \%$ stacking gel, and transferred to nitrocellulose membranes (Beyotime, Shanghai, China). The membranes were incubated with $5 \%$ nonfat dried milk in TBS with $0.1 \%$ Tween-20 (TBST) for blocking, and then incubated with $6 \times$ His-tag mouse monoclonal antibody (1:2500 dilution, EnoGene Biotech, Nanjing, China). After washing with TBST, the membranes were incubated with appropriate horseradish peroxidase (HRP)-conjugated goat anti-mouse IgG (1:5000 dilution, EnoGene Biotech, Nanjing, China). Finally, the immunoreactive proteins were detected with BeyoECL Star (Beyotime, Shanghai, China).

\section{Purification of the recombinant HsUBIAD1}

The intracellular proteins previously extracted were concentrated and subjected to subsequent purification using Ni-NTA affinity chromatography. The crude enzyme solution was purified with a Ni-NTA Sefinose ${ }^{\mathrm{TM}}$ Resin Kit (BBI, UK) according to the manufacturer's specifications. Then the eluent was passed through a desalting gravity column (BBI, UK) to remove the salts. The purified proteins of $H s$ UBIAD1 were frozen and stored at $-80{ }^{\circ} \mathrm{C}$ in preparation for subsequent experiments.

\section{Enzymatic assay of HsUBIAD1}

The enzymatic reaction for $H s \mathrm{UBIAD} 1$ was conducted in vitro and the conditions were adjusted according to 
the method of Hirota et al. [1]. Reactions were initially performed in $1 \mathrm{~mL}$ of $100 \mathrm{mM}$ Tris- $\mathrm{HCl}$ (pH 8.0) containing $1 \mathrm{mM}$ DTT, $10 \mu \mathrm{M} \mathrm{GGPP}, 10 \mu \mathrm{MVK} \mathrm{VK}_{1}$ or $\mathrm{VK}_{3}$ and $10 \mathrm{mg}$ of $H s \mathrm{UBIAD} 1$ protein. Reaction mixtures were incubated at $37^{\circ} \mathrm{C}$ for $1 \mathrm{~h}$, and then stopped by the addition of $1 \mathrm{~mL}$ of methanol, and the organic phase was used for HPLC analysis. The activity of HsUBIAD1 was measured at different $\mathrm{pH}$ and temperature values in the presence of different metallic ions, and the initial activity of $H s$ UBIAD1 was measured without metal ions at $\mathrm{pH} 8.0$ and $37^{\circ} \mathrm{C}$. The reported values of relative activity are the averages of triplicate trials.

Additionally, we analyzed the enzymatic reaction conditions of $H s$ UBIAD1 in vivo using the whole-cell catalytic system. After $36 \mathrm{~h}$ of fermentation, $\mathrm{VK}_{3}(10 \mathrm{mg} / \mathrm{L}$, in methanol $)$ and $\mathrm{MgCl}_{2}(10 \mathrm{mM})$ were added to the catalysis mixture, which was incubated at $31{ }^{\circ} \mathrm{C}$ for to realize the subsequent catalytic reaction. Subsequently, the catalytic products were extracted and detected.

\section{Transformation and screening of high-yield MK-4 producing $P$. pastoris}

The recombinant plasmids pGrG and pGrIG were linearized by the restriction enzyme SpeI for integration into the rDNA locus, and electroporated into the electrocompetent cells of the high-yield strain GGU-23 to generate GGU-GrG and GGU-GrIG, respectively. Transformants were selected on histidine-deficient MD agar plates containing $500 \mu \mathrm{g} / \mathrm{mL}$ Zeocin. Then, colony PCR analysis was rapidly performed to identify the presence of the expression cassette using the pGAP-F/3'AOX1 primer pairs listed in Additional file 1: Table S3. To screen the high-yield MK-4 producing P. pastoris, the positive transformants GGU-GrG and GGU-GrIG were inoculated and subsequently treated as described previously.

\section{Extraction and analysis of MK-4}

To extract a certain amount of MK-4 to be used for analysis, the recombinant $P$. pastoris was cultured according to the previous method. After fermentation and whole cell catalysis, $25 \mathrm{~mL}$ of fermented broth were centrifuged at $13,000 \times g$ for $5 \mathrm{~min}$ at $4{ }^{\circ} \mathrm{C}$ and dried in a vacuum freeze dryer for $6-8 \mathrm{~h}$. The biomass of each recombinant was determined by weighing the freeze-dried cell mass, then methanol $(5 \mathrm{~mL})$ was added, followed by static extraction for $2 \mathrm{~h}$. Then $\mathrm{n}$-butyl alcohol $(5 \mathrm{~mL})$ was added to the supernatants and the extraction mixture was oscillated for $2 \mathrm{~h}$ at $150 \mathrm{rpm}$. The organic phase was centrifuged at $13,000 \times g$ for $10 \mathrm{~min}$ and filtered through $0.45 \mu \mathrm{m}$ pore organic membranes. Both intracellular and extracellular MK-4 levels were analyzed by high performance liquid chromatography (HPLC). Methanol and dichloromethane were selected to be the mobile phase at a ratio of 4:1 $(\mathrm{v} / \mathrm{v})$. The detector was operated at the wavelength of $248 \mathrm{~nm}$ for the quantitative detection of MK-4, at which the menaquinones exhibited a strong UV absorption. The contents of MK-4 were calculated from the peak areas based on standard curves of MK-4. Then, the prenylated products were analyzed using a liquid chromatography mass spectrometry (LC-MS) system equipped with LTQ Orbitrap XL ETD analyzer (Thermo Fisher Scientific, USA).

\section{Results \\ Bioinformatics analysis of HsUBIAD1}

The analysis results of SOPMA showed that $H s$ UBIAD1 consists of $49.70 \%$ alpha helices, $18.34 \%$ extended strands, $5.03 \% \beta$-turns and $26.92 \%$ random coils (Additional file 1 : Figure S1). The prediction results of ProtScale showed a GRVAY (Grand average of hydropathicity) value of 0.528 , indicating that $H s$ UBIAD1 is a hydrophobin, which was consistent with the predictions of SOSUI (Additional file 1: Figure S2). In addition, the hydrophobicity plots generated by DNAMAN showed that significant hydrophobic domains appear in the potential transmembrane region predicted by Phobius (Additional file 1: Figure S3). The prediction results of SignalP 3.0 using neural networks $(\mathrm{NN})$ and hidden Markov models (HMM) indicated that native $H s \mathrm{UBIAD} 1$ has no signal peptide or signal anchor. In other words, HsUBIADlis a nonsecretory protein. Based on the results of WoLF PSORT, $H s \mathrm{UBIAD} 1$ was predicted to contain a KKXX-like motif (SLPK) in the C-terminus, which was regarded as an endoplasmic reticulum (ER) membrane retention signal.

$H s$ UBIAD1 was identified as a typical multi-spanning integral membrane protein according to the results of 13 transmembrane topology predictors, whereas different analysis software predicted a number of transmembrane helical segments (TMHs) ranging from 7 to 9 (Additional file 1: Table S4). Hence, the exact number of TMHs has not been determined from the current results. On the flip side, the forecasted results of most predictions indicated that the N-terminus of $H s$ UBIAD1 was located on the cytoplasmic side of the membrane (Additional file 1: Figure S4). And the tertiary structure of $H s$ UBIAD1 was predicted to contain $9 \alpha$-helices generated with the SWISS-MODEL program, using the ApUbiA (Aeropyrum pernix, 4-hydroxybenzoate octaprenyltransferase) structure as a template (Additional file 1: Figure S5).

The aromatic prenyltransferase (aPT) catalyzes the transfer of the isopentene group into the aromatic nucleus, and can be classified into two types, membranebound and soluble, according to bioinformatics analysis. The phylogenetic tree was constructed with the neighbor-joining method based on the Poisson model to show the relationship between $H s \mathrm{UBIAD} 1$ and other aPTs. The 
results showed that $H s$ UBIAD1 is located in the membrane-bound clade rather than the soluble clade. Moreover, $H s$ UBIAD1 should belong to the menA family rather than the UbiA family (Fig. 2a).

Next, multiple sequence alignments were carried out among several membrane-bound aromatic prenyltransferases and the results indicated that members of the menA family contain two aspartate-rich motifs (NxxxDxxxxxD and DxxxD) (Fig. 2b). Similar to the conserved motifs of the UbiA family, the conserved domains of $H s \mathrm{UBIAD} 1$ were presumed to be the recognition site of the isoprenyl side chain.

\section{Construction of the MK-4 biosynthetic pathway in $P$. pastoris}

In order to improve the expression level of $H s$ UBIAD1 in $P$. pastoris, we performed a codon optimization of the original $H s$ UBIAD1. After codon optimization, 242 bases were substituted and 210 codons were modified, and the codon adaptation index (CAI) was significantly increased from 0.59 to 0.85 , which is considered to be suitable for good expression of HsUBIAD1 according to the GenScript Web server. The original and codonoptimized synthetic sequences of $H s$ UBIAD1 are shown in Additional file 1: Figure S6. Furthermore, for efficient initiation of translation, the Kozak sequence (GCCACC) was introduced in front of the initiation codon by primer UBIAD1-F-EcoRI.

Moreover, to compare the effects of different promoters on protein expression levels, the expression vectors pGAPZA and PPICZA were used to produce recombinant HsUBIAD1, that contains the constitutive promoter $\mathrm{P}_{\mathrm{GAP}}$ and the methanol inducible promoter $\mathrm{P}_{\mathrm{AOX} 1}$, respectively. As shown in Additional file 1: Figure S7a, the PCR product was amplified and cloned into the $E c o R I$ and NotI sites of pGAPZA and pPICZA, to generate recombinant $\mathrm{pGU}$ and $\mathrm{pPU}$ vectors, respectively. The results of sequencing verified that the presence and correct orientation of the $H s$ UBIAD1 ORF.

\section{Transformation and screening of recombinant HsUBIAD1 producing $P$. pastoris}

The desired recombinant plasmids were obtained after selection and verification, and 5-10 $\mu \mathrm{g}$ of plasmid DNA were linearized and condensed, and resuspended in 10 $\mu \mathrm{L}$ of ultrapure water, which was electroporated into the electrocompetent cells of $P$. pastoris GS115. The expression vectors pGAPZA and pPICZA contained the HIS4 gene and Zeocin ${ }^{\mathrm{TM}}$ resistance gene, which can be used as selectable markers for screening of recombinant $\mathrm{Hs} \mathrm{UB}$ IAD1. The result of colony PCR and sequencing showed that the expression cassette was inserted successfully into the GS115 genome. The results of the dot-blotting assay showed that the relative expression level of $H s$ UBIAD1 in recombinant GGU was obviously superior to that of GPU (Additional file 1: Figure S8). In particular, GGU-23 (E4) gave $105.8 \%$ higher $H s$ UBIAD1 production, when compared with that of GPU-23 (E8), which was selected as the high-yield $H s \mathrm{UBIAD} 1$-producing strain.

\section{Effects of culture conditions on HsUBIAD1 expression level in recombinant GGU-23}

The analysis of the western blot results showed a band between 35 and $45 \mathrm{kDa}$ in samples from recombinant GGU-23 that was not present in the negative control (Fig. 3). And the molecular weight of native $H s$ UBIAD1 was calculated based on the aminoacid sequence as $37 \mathrm{kDa}$, which means that the exogenous $H s$ UBIAD1 was successfully expressed in the recombinant $P$. pastoris strains. To improve the expression level of $H s$ UBIAD1 in recombinant GGU-23, the initial $\mathrm{pH}$ and culture temperature during the fermentation processes were optimized. The production of $H s \mathrm{UBIAD} 1$ increased by 4.37 times upon after incubation at $\mathrm{pH} 7.0$ and $24{ }^{\circ} \mathrm{C}$ for $36 \mathrm{~h}$, when compared with that under the initial conditions (Fig. 4).

\section{Enzymatic assays of HsUBIAD1}

In this study, the effects of $\mathrm{pH}$, temperature and metal ions on the activity of $H s$ UBIAD1 in vitro were investigated. After optimization, the most appropriate $\mathrm{pH}$ was 7.0 and the most appropriate temperature was $31{ }^{\circ} \mathrm{C}$ for MK-4 production in the presence of $\mathrm{Mg}^{2+}$ (Fig. 5). Under the optimum conditions, the activity of $H s$ UBIAD1 was $229 \%$ higher than before. The results indicated that metal ions were not required for the synthesis of MK-4 catalyzed by $H s$ UBIAD1, but the addition of $\mathrm{Mg}^{2+}$ and $\mathrm{Na}^{+}$improved the catalytic activity while $\mathrm{Fe}^{2+}, \mathrm{Ca}^{2+}$ and $\mathrm{Mn}^{2+}$ inhibited the prenylation reaction to some extent.

\footnotetext{
(See figure on next page.)

Fig. 2 Bioinformatic analysis of the aromatic prenyltransferase (aPT) HsUBIAD1. a Phylogenetic analysis of HsUBIAD1 with the Mega X program. The phylogenetic tree was divided into two distinct clades: blue, UbiA family of membrane-bound aromatic prenyltransferases; green, menA family of membrane-bound aromatic prenyltransferases; yellow, soluble aromatic prenyltransferases. $\mathbf{b}$ Multiple sequence alignment of HsUBIAD1. The two conserved aspartate-rich motifs characteristic of the membrane-bound aromatic prenyltransferases, Ap, Aeropyrum pernix; At, Arabidopsis thaliana; Ec, Escherichia coli; Le, Lithospermum erythrorhizon; Os, Oryza sativa; Sc, Saccharomyces cerevisiae; BI, Bifidobacterium longum; Kp, Klebsiella pneumoniae; Pa, Papio anubis; Pt, Piliocolobus tephrosceles; Hs, Homo sapiens
} 
a

$\underset{\text { Aptbia }}{\text { b }}$

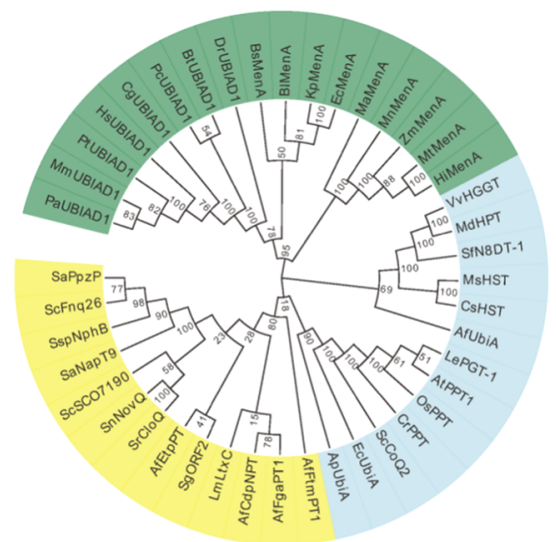

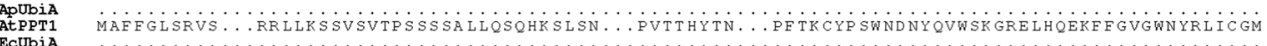

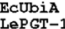

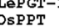
$\operatorname{scc} \propto 2$

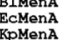

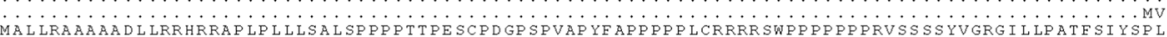

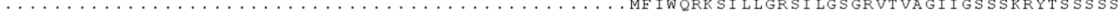

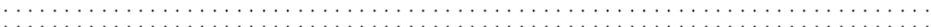

MAASQVi MAASQIL
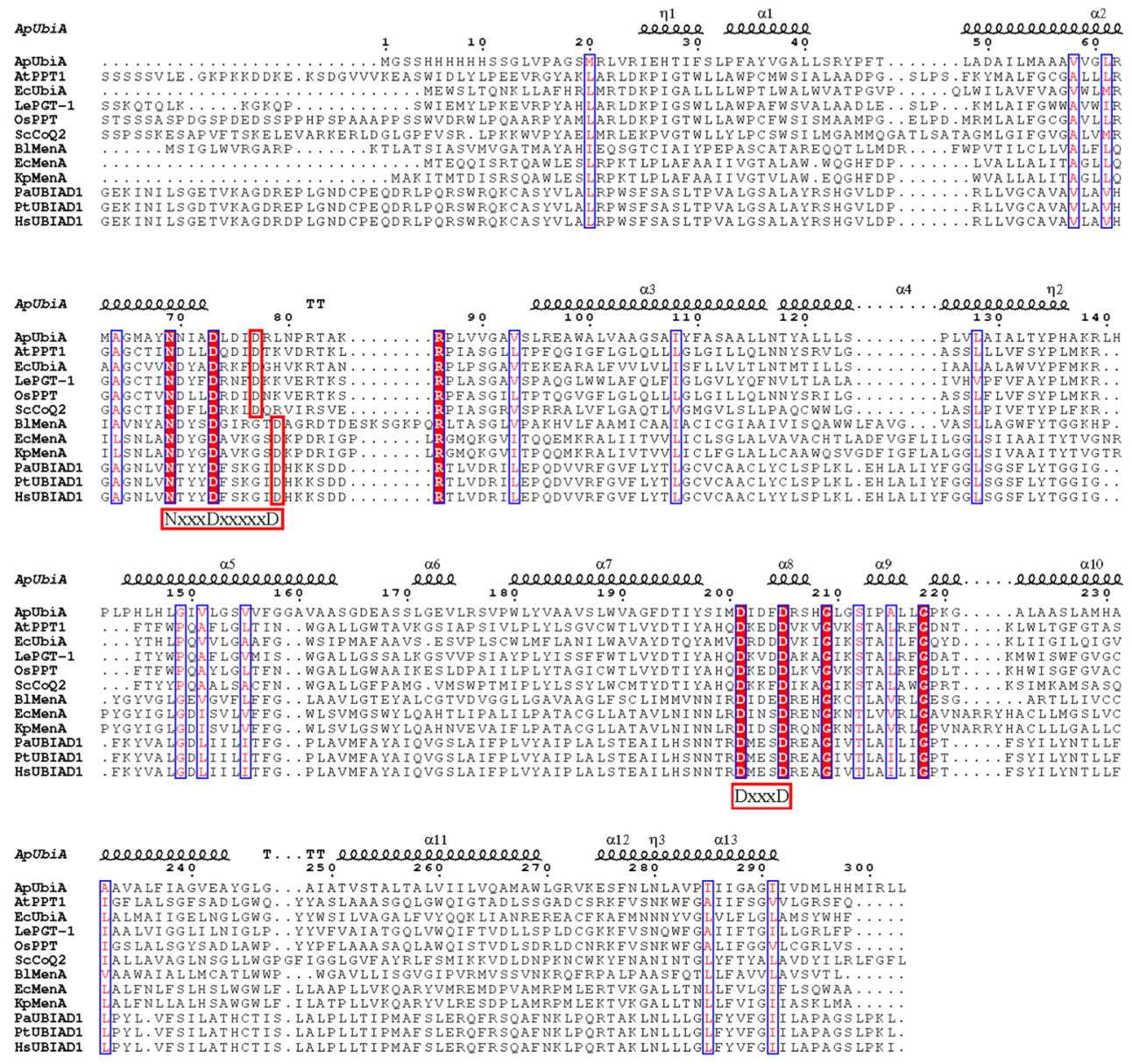


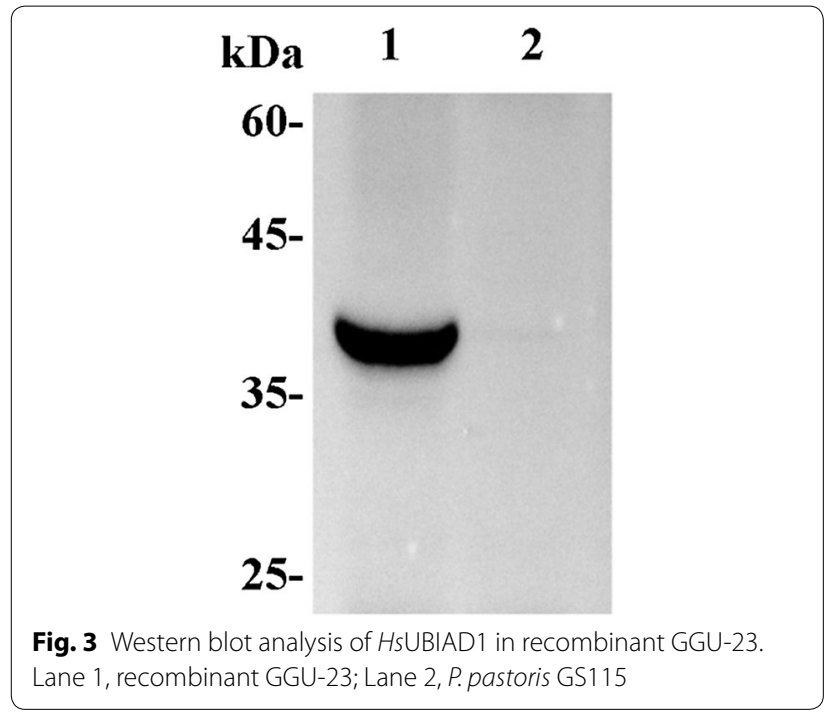

After $36 \mathrm{~h}$ of fermentation, $\mathrm{VK}_{3}$ was directly added as the prenyl acceptor to the fermentation broth for prolonged cultivation without changing the medium, which was incubated at $31{ }^{\circ} \mathrm{C}$ for another $18 \mathrm{~h}$. In this case, it is believed that $\mathrm{Mg}^{2+}$ promotes the binding of substrate GGPP to HsUBIAD1, although MK-4 could be biosynthesized in the absence of $\mathrm{Mg}^{2+}$.

\section{Improving GGPP supply to increase the yield of intracellular MK-4}

To further increase the production of MK-4, we attempted to improve the supply of GGPP by heterogenous expression of $\mathrm{SaGGPPS}$ and fusion expression of $P p$ IDI and SaGGPPS (Additional file 1: Figure S7b). The expression cassettes were integrated into the rDNA locus rather than the GAP locus to increase the copy number. After transformation, recombinant strains of GGUGrG and GGU-GrIG were cultured in test tubes prior to screening the high-yield strains for MK-4 production. The results of colony PCR confirmed that either pGrG or pGrIG was present in the the genomic DNA of the recombinant GGU-23. According to the HPLC results, a novel prenylated product appeared at $7.1 \mathrm{~min}$ compared to wild-type GS115, which was basically consistent with MK-4 standards (Fig. 6a). The mass spectrometric analysis of the prenylated product displayed a peak with $\mathrm{m} / \mathrm{z}=445$, which corresponds to the hydrogen adduct cation of MK-4 (Fig. 6b). It was confirmed that MK-4 was predominantly biosynthesized intracellularly but was not detected in the supernatant. Furthermore, GGU-GrIG afforded 140\% higher MK-4 production, when compared with that noted in GGU-GrG (Fig. 7). The yield of intracellular MK-4 was significantly improved to $0.24 \mathrm{mg} / \mathrm{g}$ DCW when additional GGPP was supplied.

\section{Discussion}

In recent decades, $P$. pastoris has become a mature and efficient expression system for recombinant exogenous proteins production. Above all, P. pastoris is easy to manipulate genetically, quickly grows to very high cell density in a relatively simple and inexpensive medium, and is able to secrete large amounts of recombinant proteins [21]. Furthermore, unlike the prokaryotic expression systems, P. pastoris has a eukaryotic posttranslational modification system, which can facilitate expression of correctly-folded eukaryotic proteins [18, $42,43]$. And plasmids integrated into the genome by homologous recombination are not easily lost from their host, resulting in enhanced stability of the recombinant strain. However, due to the lack of native pathway for the biosynthesis of the naphthoquinone precursor, P. pastoris cannot synthesize menaquinone by itself. Moreover, if the de novo synthesis pathway of naphthoquinone ring is constructed, a series of enzymes need to be heterologously expressed, which involves complex regulation and time-consuming screening processes. Considering various aspects, it is more economically viable to exogenously add the naphthoquinone precursor analog $\mathrm{VK}_{3}$ into the reaction system than to introduce an exogenous synthetic pathway in $P$. pastoris. Therefore, we attempted to achieve the synthesis of MK-4 by heterologous expression of the key enzyme that catalyzes the polymerization of the naphthoquinone ring and isopentenyl side chain rather than a series of enzymes. In the past, many papers and much research has suggested that $H s$ UBIAD1 is an efficient MK-4 biosynthetic enzyme that may have both side-chain cleavage and prenylation activities, as it is an aPT homologous to EcMenA [1, 2, 4, 6]. Previous studies have also suggested that $H s$ UBIAD1 should belong to the UbiA family. But with the deepening of research, $H s$ UBIAD1 is currently considered to belong to the menA family rather than the UbiA family, which is completely consistent with the analysis of the phylogenetic tree in this study. Besides, the discrepancy in prediction results was due to the different algorithms of the different transmembrane topology predictors. $H s$ UBIAD1 should contain 9 TMHs based on a comprehensive analysis of the transmembrane topology and hydrophobicity. This conclusion was reached for reference only, and the exact transmembrane topology of $H s \mathrm{UBIAD} 1$ remain uncertain. Since the structure and function of proteins are closely related, predicting the physicochemical properties and structure of proteins, and analyzing their genetic relationships can lay a good theoretical foundation for the study of subsequent related protein functions and mechanisms. We confirmed that HsUBIAD1 is a membrane-bound aromatic prenyltransferase by bioinformatics analysis, which affects the selection of subsequent 
a

\section{$20^{\circ} \mathrm{C} \quad 22^{\circ} \mathrm{C} \quad 24^{\circ} \mathrm{C} \quad 26^{\circ} \mathrm{C} \quad 28^{\circ} \mathrm{C} \quad 30^{\circ} \mathrm{C}$}

Hs UBIAD1

$\beta$-actin

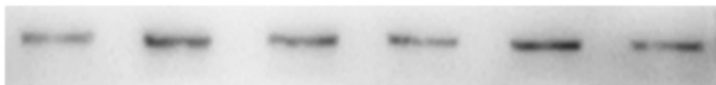

b

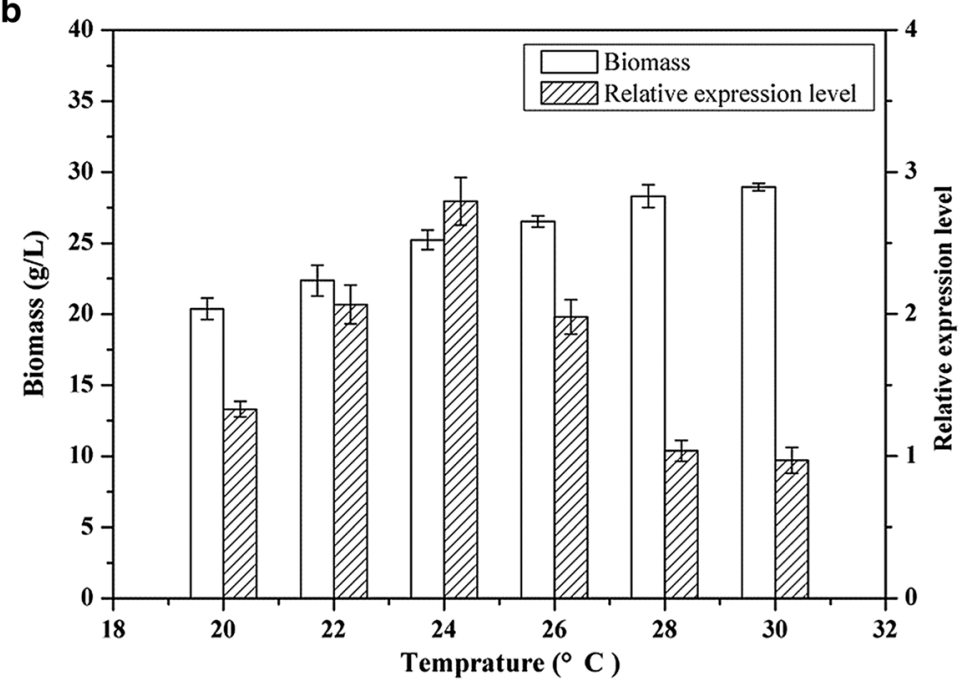

C

$\begin{array}{llllll}4.0 & 5.0 & 6.0 & 7.0 & 8.0 & 9.0\end{array}$

HsUBIAD1

$\beta$-actin

d

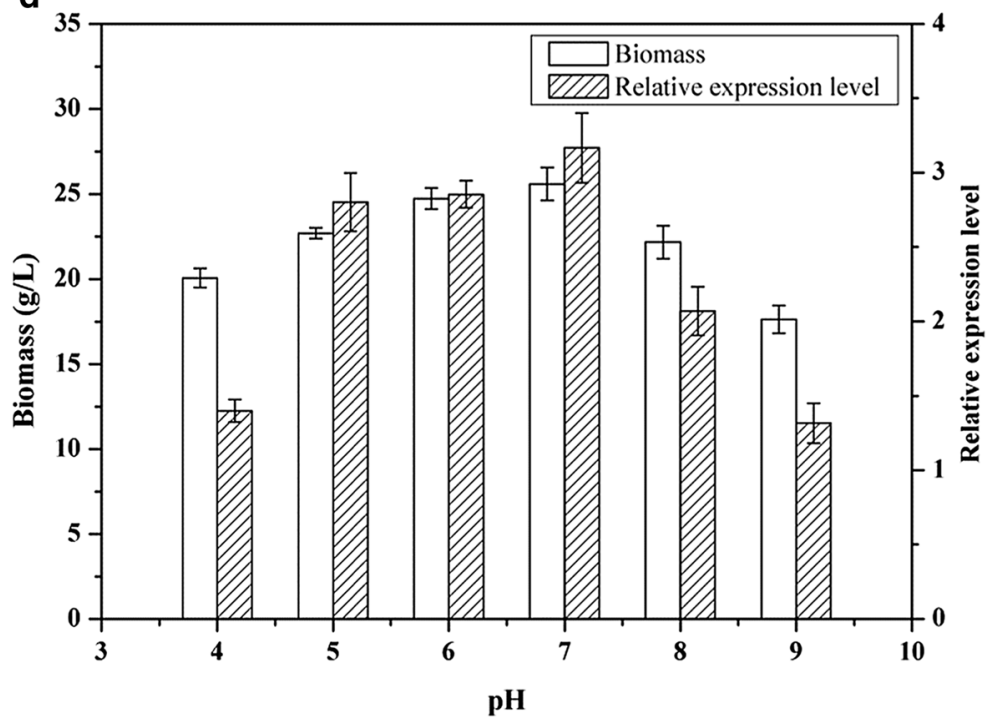

Fig. 4 Effects of culture condition on the expression level of HsUBIAD1. a Western blot analysis of HsUBIAD1 at different temperature (at initial pH 6.0, for 24 h); b The expression of Hs UBIAD1 at different temperature (at initial pH 6.0, for 24 h); c Western blot analysis of HsUBIAD1 at different initial $\mathrm{pH}$ (at $24^{\circ} \mathrm{C}$, for $24 \mathrm{~h}$ ); $\mathbf{d}$ The expression of HsUBIAD1 at different initial $\mathrm{pH}$ (at $24^{\circ} \mathrm{C}$, for $24 \mathrm{~h}$ ); e Western blot analysis of HsUBIAD1 for different time (at initial $\mathrm{pH} 7.0$, at $24^{\circ} \mathrm{C}$ ); $\mathbf{f}$ The expression of $\mathrm{Hs} \cup B I \mathrm{AD} 1$ for different time (at initial $\mathrm{pH} 7.0$, at $24^{\circ} \mathrm{C}$ ) 

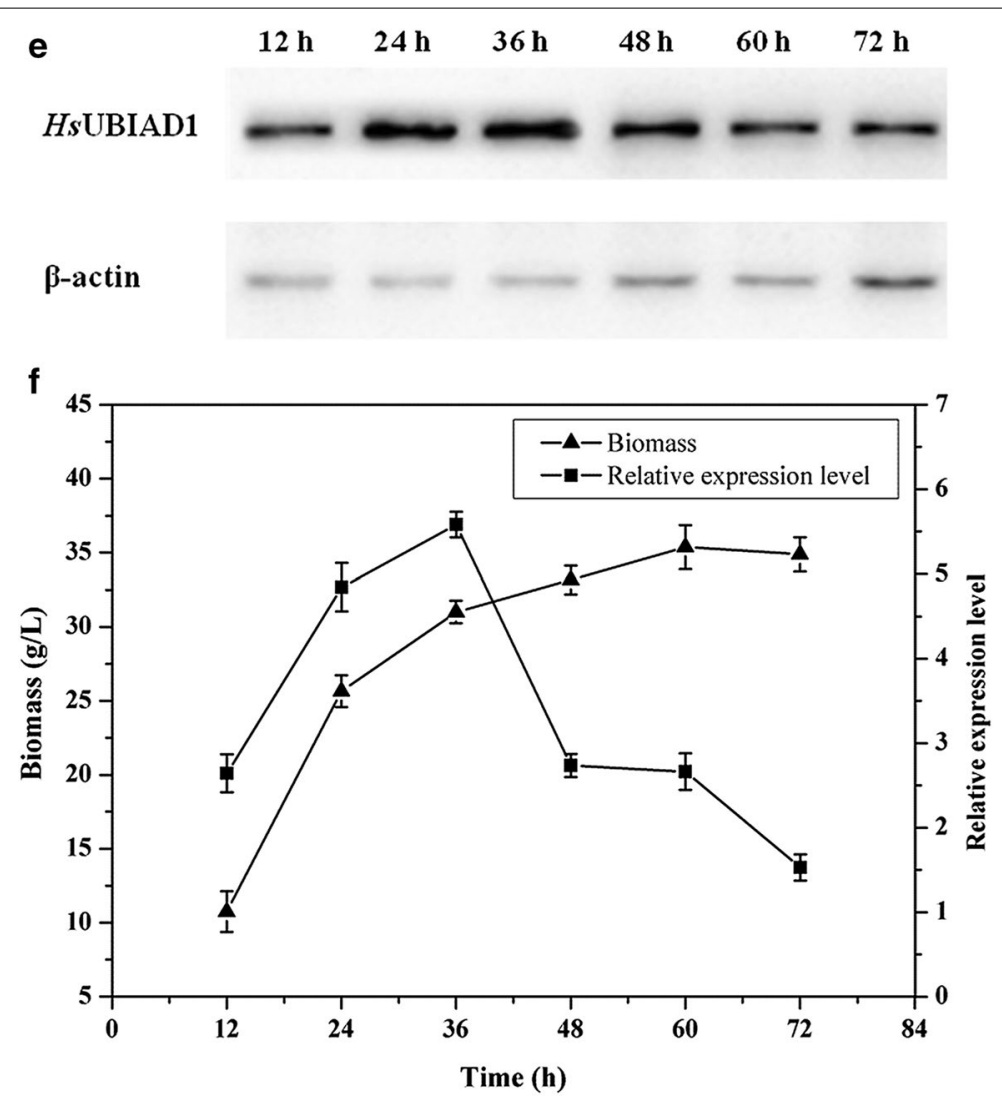

Fig. 4 continued

expression and purification strategies. In this study, we successfully constructed a heterologous expression vector for the efficient expression of $H s \mathrm{UBIAD} 1$ in $P$. pastoris. The recombinant plasmids contain the HIS4 gene and Zeocin $^{\mathrm{TM}}$ resistance gene as the selectable markers, and the $H s$ UBIAD1 fragment was integrated into the $\mathrm{P}_{G A P}$ locus of the chromosome by homologous recombination. At the same time, we also found that $\mathrm{P}_{G A P}$ was a strong constitutive promoter that can be used without methanol induction, which makes it possible to regulate the fermentation process safely and simply. Glycerol was used as the sole carbon source during the whole fermentation process to avoid adding methanol; as it was not necessary to shift cultures from one carbon source to another, strain growth was more straightforward. As an important regulatory element, the performance of the promoter directly affects the transcription level of the gene. It is gratifying that the expression level of $H s$ UBIAD1 was improved by $105.8 \%$ and the fermentation time was shortened by half under the control of $\mathrm{P}_{G A P}$ in this study.

On the one hand, the highest yield of HsUBIAD1 was obtained at $\mathrm{pH}$ 7.0, which was suitable for biomass growth of GGU-23. The theoretical isoelectric point (pI) was calculated based on the $H s$ UBIAD1 aminoacid sequence as 8.4. Thus, it is assumed that the low expression level of $H s \mathrm{UBIAD} 1$ may be caused by the alkaline environment, which may inhibit the correct folding and stability of the $H s \mathrm{UBIAD} 1$ protein. On the other hand, the optimal culture temperature was $24{ }^{\circ} \mathrm{C}$ for the expression of $H s \mathrm{UBIAD} 1$, although higher temperatures were more conducive to the growth of the cells. It is possible that low temperature culture facilitated the expression and proper folding of $H s \mathrm{UBIAD} 1$. By optimizing the expression conditions, the production of HsUBIAD1 increased by 4.37 times upon incubation at $\mathrm{pH} 7.0$ and $24{ }^{\circ} \mathrm{C}$ for $36 \mathrm{~h}$, when compared to the initial conditions ( $\mathrm{pH}$ of 6.0 and induced at $28^{\circ} \mathrm{C}$ for $24 \mathrm{~h}$ ). Similar to these results, a low temperature culture has been shown to promote the expression of exogenous proteins in $P$. pastoris based on recent studies [42, 44, 45].

Herein, the results have demonstrated that $H s$ UBIAD1 expressed in $P$. pastoris has the ability to catalyze the biosynthesis of MK-4. Previous studies have shown that $\mathrm{Mg}^{2+}$ plays a key role in binding the side-chain of substrates to $H s$ UBIAD1 $[1,2]$. However, Hirota et al. have reported that $\mathrm{Mg}^{2+}$ was necessary for recognizing and activating the short-chain isoprenyl substrates GPP or FPP, while the larger hydrophobic region of GGPP was 

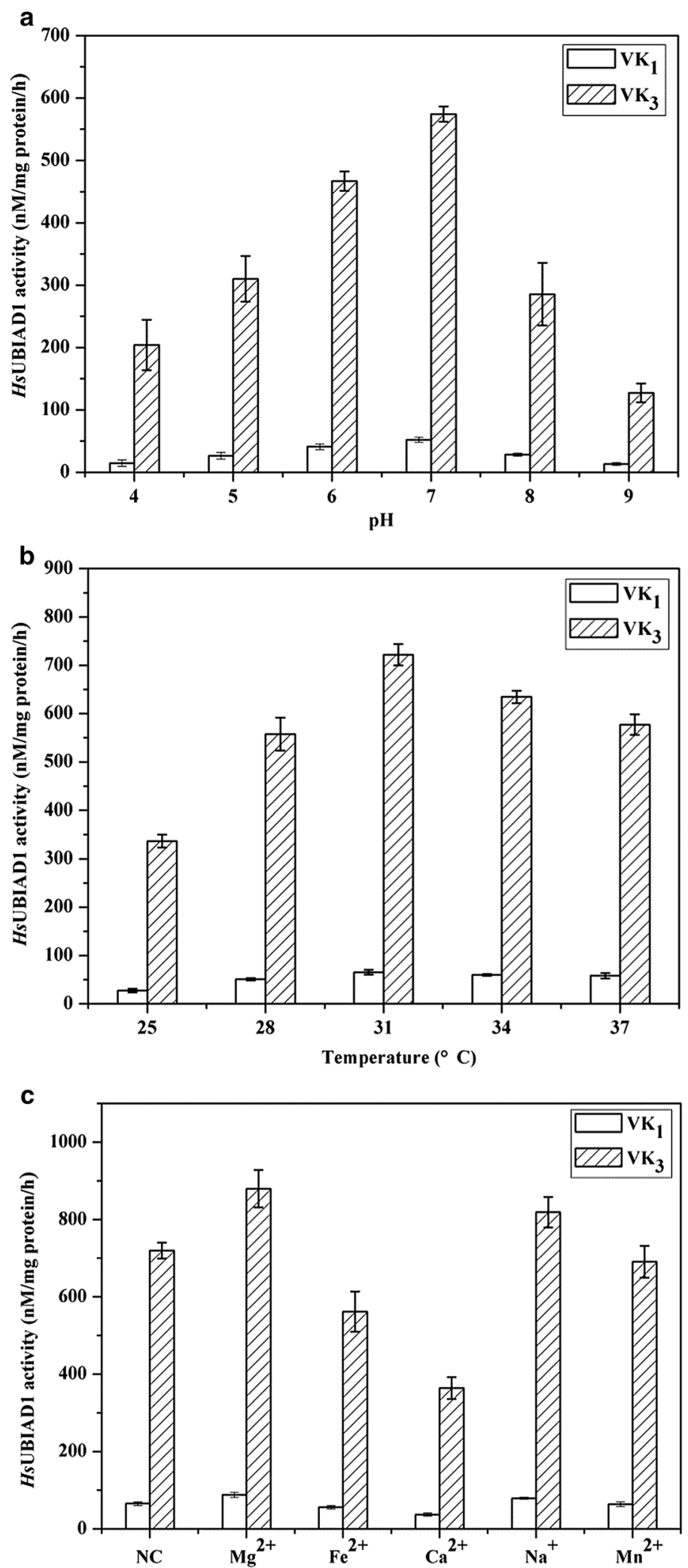

Fig. 5 Effects of reaction condition on $H s \cup B I A D 1$ activity using phylloquinone $\left(V K_{1}\right)$ and menadione $\left(V_{3}\right)$ as the donor of naphthoquinone ring. a Effects of pH on $\mathrm{Hs} \cup B I A D 1$ activity (at $37^{\circ} \mathrm{C}$, without metallic ions); $\mathbf{b}$ Effects of temperature on HsUBIAD1 activity (at initial pH 7.0, without metallic ions); c Effects of metallic ions on $\mathrm{HSUBIAD} 1$ activity (at $\mathrm{pH} 7.0$ and $31{ }^{\circ} \mathrm{C}$ ), $\mathrm{NC}$, negative control, without metallic ions 

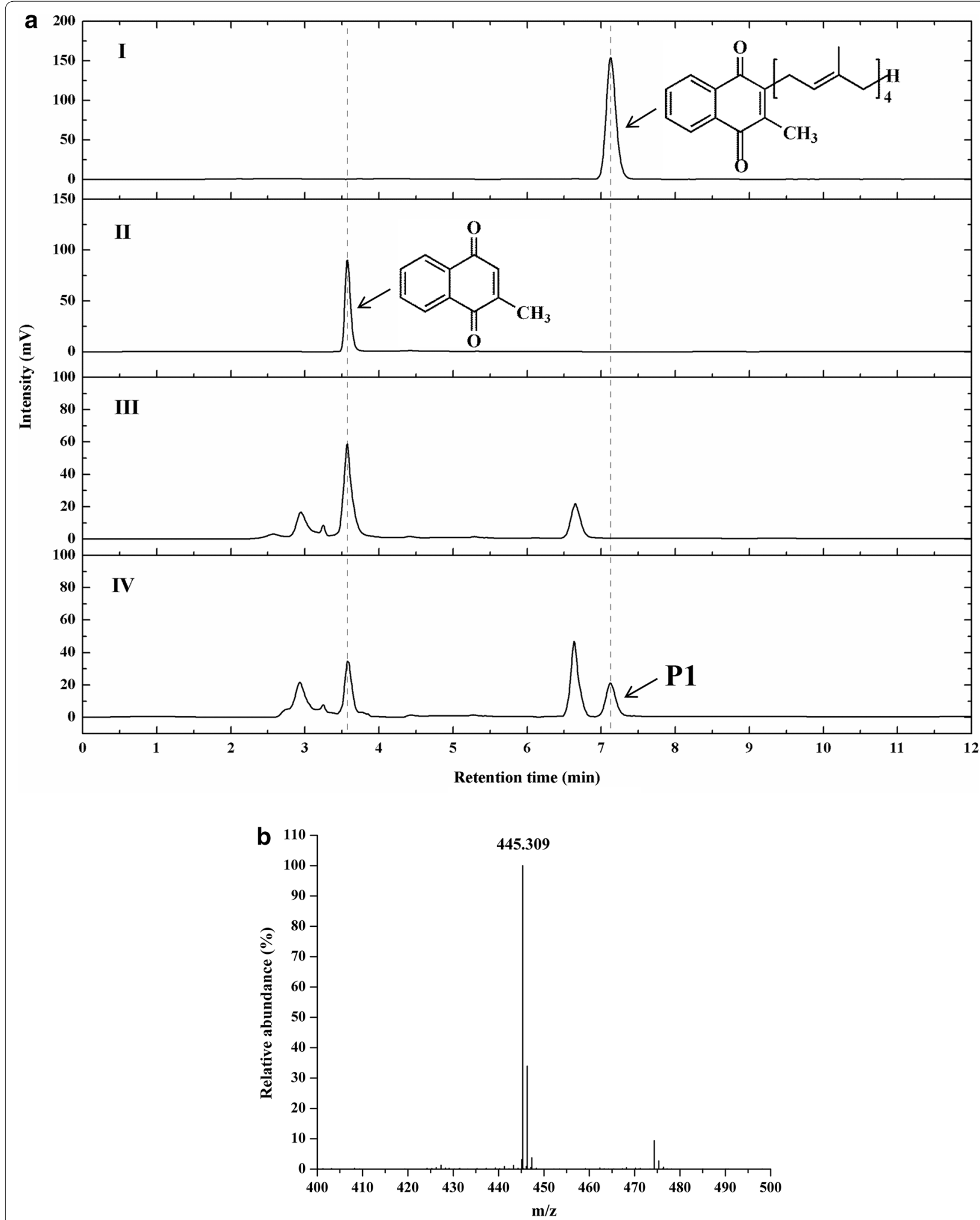

Fig. 6 Products analysis of whole-cell catalytic prenylation. a HPLC analysis of prenylated products using VK $\mathrm{K}_{3}$ as prenyl acceptor in whole-cell catalytic system. I, MK-4 standard; II, VK 3 standard; III, Intracellular catalytic products of wild-type GS115; IV, Intracellular catalytic products of recombinant GGU-GrIG. b Mass spectrometric analysis of prenylated products 


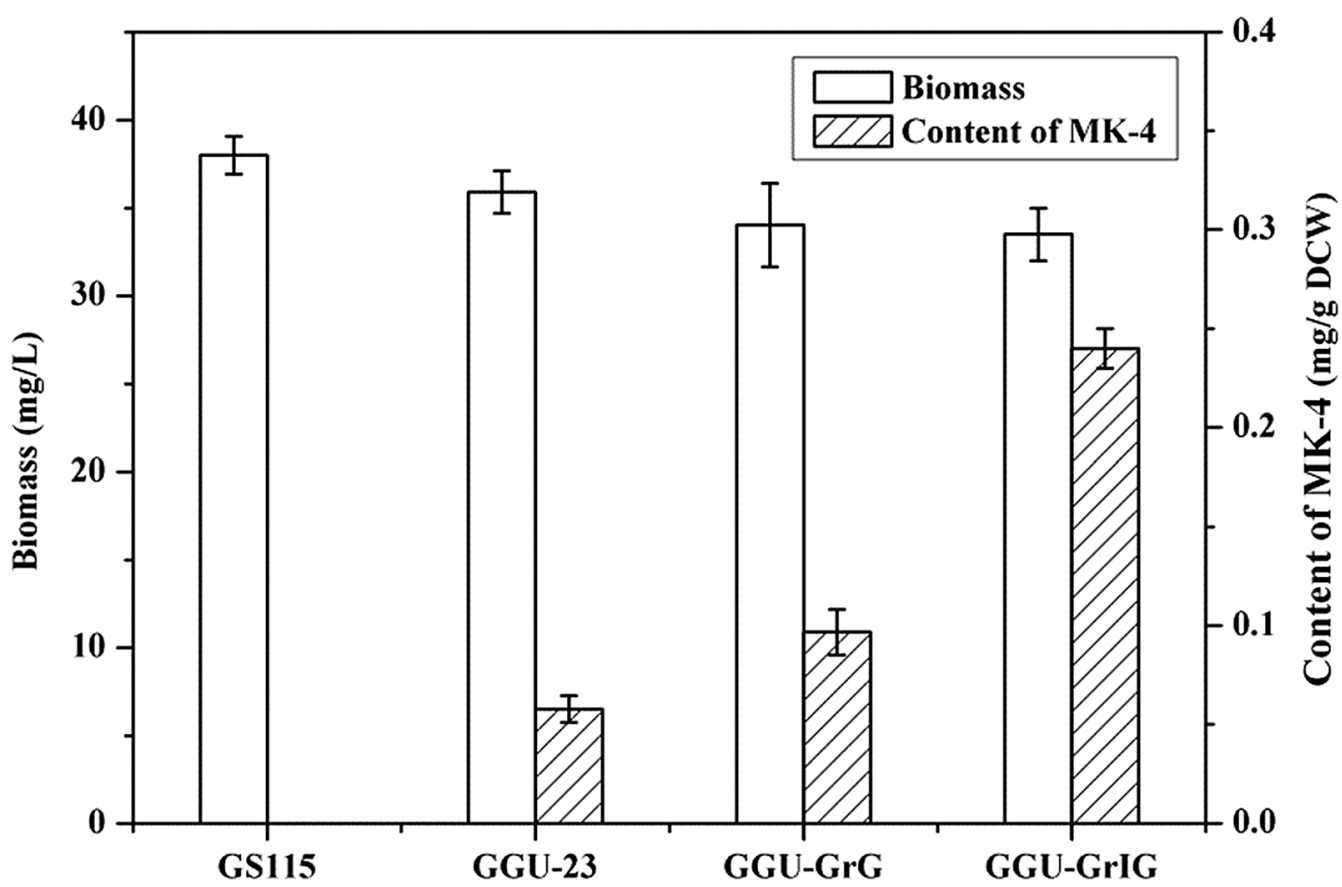

Fig. 7 The content of MK-4 in recombinant GGU-GrIG

directly recognized by $H s \mathrm{UBIAD} 1$ without the participation of $\mathrm{Mg}^{2+}$ [6]. In the present study, we found that GGPP could be recognized by $H s$ UBIAD1 and catalyze prenyl transfer to aromatic substrates with or without the participation of $\mathrm{Mg}^{2+}$. In addition, $H s$ UBIAD1 displayed higher catalytic activity when $\mathrm{VK}_{3}$ was used as the donor of a naphthoquinone ring. It is speculated that the isopentenyl side chain could be attached directly to the naphthoquinone ring of $\mathrm{VK}_{3}$, while the side chain of $\mathrm{VK}_{1}$ needs to be removed to release $\mathrm{VK}_{3}$.

However, the yield of MK-4 was low, which was caused by the low content of the side-chain substrate GGPP. To improve the intracellular GGPP supply, we attempted to heterologously express $\mathrm{SaGGPPS}$ in recombinant GGU23. In theory, there is a dose effect between the productivity of a heterologous protein and the copy number of the target gene [28]. In other words, we could improve the expression level of the protein by increasing the gene copy number within a certain range. In P. pastoris, the repeated sequence of rDNA has been used as the integration site of the expression cassettes of the target gene to obtain stable multicopy strains [46]. Similar approaches were used in the present study: we obtained stable multi-copy recombinant strains by integrating the expression cassettes of SaGGPPS into the 28S rDNA locus. Many studies have shown that SaGGPPS has the ability to biosynthesize GGPP by directly and continuously adding isoprenoid building blocks, which avoids competition with other branched pathways for FPP [35, $47,48]$. The yield of MK-4 was indeed improved by heterologous expression of SaGGPPS. On this basis, we further increased the content of GGPP by expressing SaGGPPS fused with $P p$ IDI. The purpose of the fusion expression strategy was to narrow the spatial distance between $S a$ GGPPS and P IDI and to reduce the steric hindrance of the substrates, which was able to improve the transfer efficiency of the isoprenoid building blocks and to facilitate the accumulation of the key precursor GGPP. Recently, research on multi-enzyme assembly strategies has furnished an attractive and worth-while method for promoting substrate transfer between multiple enzymes. Researchers hoped to achieve cascading amplification of target metabolites by eliminating interference from unrelated metabolic pathways. Other reported microbial stains including Escherichia coli and Bacillus subtilis have been well-documented in the biosynthesis of MKs. Liu et al. changed the state of the cell membrane in Escherichia coli, and the extracellular MK reached $10.71 \pm 0.19 \mathrm{mg} / \mathrm{L}$ after $120 \mathrm{~h}$ of cultivation [49]. Wang et al. improved the redox potential and the state of the cell membrane of $B$. subtilis natto, the MK-7 concentration increased to $43 \mathrm{mg} / \mathrm{L}$ in a 5 -L bioreactor for $144 \mathrm{~h}$ [50]. Ma et al. modified the MEP pathway in $B$. subtilis to enhance the biosynthesis of MK-7, resulting in $50 \mathrm{mg} / \mathrm{L}$ MK-7 after $120 \mathrm{~h}$ of cultivation [51]. Compared to other reported strains that synthesize MKs by de novo 
synthesis, we first achieved whole-cell catalytic synthesis of MK-4 in P. pastoris, which took only 54 h. Ultimately, the yield of MK-4 was remarkably enhanced to $0.24 \mathrm{mg} / \mathrm{g}$ $\mathrm{DCW}$ using $\mathrm{VK}_{3}$ as the prenyl acceptor.

\section{Conclusion}

In this study, we constructed a novel synthetic pathway in $P$. pastoris for the production of MK-4 by heterologous expression of $H s \mathrm{UBIAD} 1$. As a versatile and efficient expression system, $P$. pastoris has been successfully applied to the stable and efficient expression of $H s \mathrm{UB}$ IAD1. The effects of different promoters on $H s$ UBIAD1 expression levels were investigated: $\mathrm{P}_{G A P}$ was associated with a higher expression level than that obtained with $\mathrm{P}_{A O X 1}$. Moreover, $\mathrm{P}_{G A P}$ also offered significant advantages in safety and simplicity. By optimizing the expression conditions, the production of $H s$ UBIAD1 increased by 4.37 times upon incubation at $\mathrm{pH} 7.0$ and $24{ }^{\circ} \mathrm{C}$ for $36 \mathrm{~h}$. Moreover, we potentiated the biosynthesis of the key precursor GGPP in P. pastoris by fusion expression of SaGGPPS and $P p$ IDI, which improved the polymerization of isoprene units. The content of MK-4 was increased to $0.24 \mathrm{mg} / \mathrm{g}$ DCW by improving the GGPP supply when $\mathrm{VK}_{3}$ was the isopentenyl acceptor. Thus, the concept of metabolic engineering has been successfully applied to the biosynthesis of a novel high value-added prenylated product MK-4 in P. pastoris, which has great significance for theoretical research and industrial application. This scheme could be further developed and refined for the biosynthesis of other prenylated products.

\section{Supplementary information}

Supplementary information accompanies this paper at https://doi. org/10.1186/s12934-019-1215-9.

Additional file 1: Figure S1. Predicted secondary structure of HSUBIAD1 by SOPMA. Figure S2. Hydrophobicity plots of HsUBIAD1 by ProtScale and DNAMAN. Figure S3. The topology of HsUBIAD1 generated by Protter.

Figure S4. Tertiary structure prediction of HsUBIAD1. Figure S5. Sequence comparison between of codon-optimized HsUBIAD1 and original HsUBIAD1 genes. Figure S6. Construction of recombinant vectors. Figure S7. Screening for HsUBIAD1 high-yield recombinant P. pastoris. Table S1. Strain used in this study and information. Table S2. Plasmid used in this study. Table S3. Primers used in this study. Table S4. Prediction of transmembrane topology of HSUBIAD1.

\section{Acknowledgements}

The authors would especially like to thank Prof. Weihua Xiao at the laboratory of signaling transduction and transcription, University of Science and Technology of China for the kind gifts of Pichia pastoris GS115.

\section{Authors' contributions}

XS, WN, QY, HW and HT conceived and designed the research, XS carried out the majority of the experiments. XS analyzed the data and wrote the manuscript. HL, PW, LW, GZ and ZZ help to analyzed the data and revised the manuscript. All authors read and approved the final manuscript.

\section{Funding}

The present work was supported by Key research and development plan of Anhui Province (1804b06020342), Natural Science Foundation of Anhui Province (1608085QC46), Major Projects of Science and Technology in Anhui Province (17030801036), Natural Science Foundation of Anhui Province (1908085MB48) and Natural Science Foundation of Anhui Province (1908085MB43)

\section{Availability of data and materials}

All data supporting the conclusions of this study are included in this article and the additional file.

\section{Ethics approval and consent to participate}

This article does not contain any studies with human participants or animals performed by any of the authors.

\section{Consent for publication}

Not applicable.

\section{Competing interests}

The authors declare that they have no competing interests.

\section{Author details}

${ }^{1}$ Key Laboratory of High Magnetic Field and Ion Beam Physical Biology, Hefei Institutes of Physical Science, Chinese Academy of Sciences, Hefei 230031, Anhui, People's Republic of China. ${ }^{2}$ University of Science and Technology of China, Hefei 230026, Anhui, People's Republic of China.

Received: 3 June 2019 Accepted: 24 September 2019 Published online: 10 October 2019

\section{References}

1. Nakagawa K, Hirota Y, Sawada N, Yuge N, Watanabe M, Uchino Y, Okuda N, Shimomura Y, Suhara Y, Okano T. Identification of UBIAD1 as a novel human menaquinone-4 biosynthetic enzyme. Nature. 2010;468:117.

2. Nickerson Michael L, Bosley Allen D, Weiss Jayne S, Kostiha Brittany N, Hirota Yoshihisa, Brandt Wolfgang, Esposito Dominic, Kinoshita Shigeru, Wessjohann Ludger, Morham Scott G, et al. The UBIAD1 prenyltransferase links menaquinone-4 synthesis to cholesterol metabolic enzymes. Hum Mutat. 2013;34:317-29.

3. Hegarty JM, Yang H, Chi NC. UBIAD1-mediated vitamin K2 synthesis is required for vascular endothelial cell survival and development. Development. 2013;140:1713-9.

4. Nakagawa K, Sawada N, Hirota Y, Uchino Y, Suhara Y, Hasegawa T, Amizuka N, Okamoto T, Tsugawa N, Kamao M. Vitamin K2 biosynthetic enzyme, UBIAD1 is essential for embryonic development of mice. PLOS ONE. 2014;9:e104078.

5. Berenjian A, Mahanama R, Kavanagh J, Dehghani F. Vitamin K series: current status and future prospects. Crit Rev Biotechnol. 2013;35:199-208.

6. Hirota Y, Nakagawa K, Sawada N, Okuda N, Suhara Y, Uchino Y, Kimoto T, Funahashi N, Kamao M, Tsugawa N. Functional characterization of the vitamin K2 biosynthetic enzyme UBIAD1. PLOS ONE. 2015;10:e0125737.

7. Schumacher MM, Elsabrouty R, Seemann J, Jo Y, Debose-Boyd RA. The prenyltransferase UBIAD1 is the target of geranylgeraniol in degradation of HMG CoA reductase. Elife. 2015:4:e05560.

8. Rønning SB, Pedersen ME, Berg RS, Kirkhus B, Rødbotten R. Vitamin $\mathrm{K}_{2}$ improves proliferation and migration of bovine skeletal muscle cells in vitro. PLoS ONE. 2018;13:e0195432.

9. Duan F, Yu Y, Guan R, Xu Z, Liang H, Hong L. Vitamin K2 induces mitochondria-related apoptosis in human bladder cancer cells via ROS and JNK/p38 MAPK signal pathways. PLoS ONE. 2016;11:e0161886.

10. Samykutty A, Shetty AV, Dakshinamoorthy G, Kalyanasundaram R, Zheng G, Chen A, Bosland MC, Kajdacsyballa A, Gnanasekar M. Vitamin $\mathrm{K} 2$, a naturally occurring menaquinone, exerts therapeutic effects on both hormone-dependent and hormone-independent prostate cancer cells. Evid Based Complement Altern Med. 2013;2013:287358.

11. Yoshida T, Miyazawa K, Kasuga I, Yokoyama T, Minemura K, Ustumi K, Aoshima M, Ohyashiki K. Apoptosis induction of vitamin K2 in lung 
carcinoma cell lines: the possibility of vitamin K2 therapy for lung cancer. Int J Oncol. 2003;23:627-32.

12. Shearer MJ, Okano T. Key pathways and regulators of vitamin $\mathrm{K}$ function and intermediary metabolism. Ann Rev Nutr. 2018;38:127-51.

13. Morales CR, Grigoryeva LS, Pan X, Bruno L, Hickson G, Ngo MH, Mcmaster CR, Samuels ME, Pshezhetsky AV, Morales CR. Mitochondrial damage and cholesterol storage in human hepatocellular carcinoma cells with silencing of UBIAD1 gene expression. Mol Genet Metab Rep. 2014:1:407-11.

14. Yang Y, Ke N, Liu S, Li W. Structural and biochemical analysis of intramembrane prenyltransferases in the UbiA superfamily. Methods Enzymol. 2017;584:309.

15. Schumacher MM, Jun DJ, Jo Y, Seemann J, Debose-Boyd RA. Geranylgeranyl-regulated transport of the prenyltransferase UBIAD1 between membranes of the ER and Golgi. J Lipid Res. 2016;57:1286-99.

16. Huang H, Levin EJ, Liu S, Bai Y, Lockless SW, Zhou M. Structure of a membrane-embedded prenyltransferase homologous to UBIAD1. PLOS Biol. 2014;12:e1001911.

17. Wang $X$, Wang D, Jing P, Wu Y, Xia Y, Chen M, Hong L. A novel Golgi retention signal RPWS for tumor suppressor UBIAD1. Plos ONE. 2013;8:e72015.

18. Cereghino J, Cregg J. Heterologous protein expression in the methylotrophic yeast Pichia pastoris. FEMS Microbiol Rev. 2000;24:45-66.

19. Kurtzman CP. Biotechnological strains of Komagataella (Pichia) pastoris are Komagataella phaffii as determined from multigene sequence analysis. J Ind Microbiol Biotechnol. 2009;36:1435.

20. De Schutter K, Lin YC, Tiels P, Van Hecke A, Glinka S, Weber-Lehmann J, Rouzé P, Van de Peer Y, Callewaert N. Genome sequence of the recombinant protein production host Pichia pastoris. Nat Biotechnol. 2009;27:561.

21. Ahmad M, Hirz M, Pichler H, Schwab H. Protein expression in Pichia pastoris: recent achievements and perspectives for heterologous protein production. Appl Microbiol Biotechnol. 2014;98:5301-17.

22. Schwarzhans JP, Luttermann T, Geier M, Kalinowski J, Friehs K. Towards systems metabolic engineering in Pichia pastoris. Biotechnol Adv. 2017:35:681.

23. Fei L, Wang Y, Chen S. Improved glutathione production by gene expression in Pichia pastoris. Bioprocess Biosyst Eng. 2009;32:729-35.

24. Cregg JM, Madden KR, Barringer KJ, Thill GP, Stillman CA. Functional characterization of the two alcohol oxidase genes from the yeast Pichia pastoris. Mol Cell Biol. 1989;9:1316-23.

25. Peña DA, Gasser B, Zanghellini J, Steiger MG, Mattanovich D. Metabolic engineering of Pichia pastoris. Metab Eng. 2018;50:2-15.

26. Li P, Anumanthan A, Gao X-G, llangovan K, Suzara VV, Düzgünes N, Renugopalakrishnan V. Expression of recombinant proteins in Pichia Pastoris. Appl Biochem Biotechnol. 2007;142:105-24.

27. Macauleypatrick S, Fazenda ML, Mcneil B, Harvey LM. Heterologous protein production using the Pichia pastoris expression system. Yeast. 2010;22:249-70.

28. Cheng L, Ying L, Zheng X, Pang N, Liao X, Liu X, Huang Y, Liang S. Combined strategies for improving expression of Citrobacter amalonaticus phytase in Pichia pastoris. BMC Biotechnol. 2015;15:1-11.

29. Yang Z, Zhang Z. Engineering strategies for enhanced production of protein and bio-products in Pichia pastoris: a review. Biotechnol Adv. 2018:36:182-95.

30. Tschopp JF, Brust PF, Cregg JM, Stillman CA, Gingeras TR. Expression of the lacZ gene from two methanol-regulated promoters in Pichia pastoris. Nucleic Acids Res. 1987;15:3859.

31. Wu JM, Lin JC, Chieng LL, Lee CK, Hsu TA. Combined use of and promoter to enhance the expression of human granulocyte-macrophage colony-stimulating factor in Pichia pastoris. Enzyme Microb Technol. 2003:33:453-9.

32. Majidzadeh-A K, Khalaj V, Fatemeh D, Mahdi H, Farzaneh B, Ahmad A, Mahboudi F. Cloning and expression of functional full-length human tissue plasminogen activator in Pichia pastoris. Appl Biochem Biotechnol. 2010;162:2037-48.

33. Waterham HR, Digan ME, Koutz PJ, Lair SV, Cregg JM. Isolation of the Pichia pastoris glyceraldehyde-3-phosphate dehydrogenase gene and regulation and use of its promoter. Gene. 1997;186:37-44.
34. Yang M, Teymorian S, Olivares P, Murthy P. Extracellular expression of alkaline phytase in Pichia pastoris: Influence of signal peptides, promoters and growth medium. Biotechnol Rep. 2015;6:112-8.

35. Engels B, Dahm P, Jennewein S. Metabolic engineering of taxadiene biosynthesis in yeast as a first step towards Taxol (Paclitaxel) production. Metab Eng. 2008;10:201-6.

36. Wang CW, Oh MK, Liao JC. Engineered isoprenoid pathway enhances astaxanthin production in Escherichia coli. Biotechnol Bioeng. 1999:62:235-41.

37. Ohnuma S, Suzuki M, Nishino T. Archaebacterial ether-linked lipid biosynthetic gene. Expression cloning, sequencing, and characterization of geranylgeranyl-diphosphate synthase. J Biol Chem. 1994;269:14792.

38. Li Z, Zhao G, Liu H, Guo Y, Wu H, Sun X, Wu X, Zheng Z. Biotransformation of menadione to its prenylated derivative MK-3 using recombinant Pichia pastoris. J Ind Microbiol Biotechnol. 2017;44:1-13.

39. Geourjon C, Deleage G. SOPMA: Significant improvements in protein secondary structure prediction by consensus prediction from multiple alignments. Comput Appl Biosci. 1995;11:681-4.

40. Bendtsen JD, Nielsen H, von Heijne G, Brunak S. Improved prediction of signal peptides: SignalP 3.0. J Mol Biol. 2004;340:783-95.

41. Horton P, Park K-J, Obayashi T, Fujita N, Harada H, Adams-Collier CJ, Nakai K. WoLF PSORT: protein localization predictor. Nucleic Acids Res. 2007;35:W585-7.

42. Cos O, Ramon R, Montesinos JL, Valero F. Operational strategies, monitoring and control of heterologous protein production in the methylotrophic yeast Pichia pastoris under different promoters: a review. Microb Cell Fact. 2006;5:17.

43. Cereghino GPL, Cereghino JL, Ilgen C, Cregg JM. Production of recombinant proteins in fermenter cultures of the yeast Pichia pastoris. Curr Opin Biotechnol. 2002;13:329-32.

44. Hong F, Meinander NQ, Jonsson LJ. Fermentation strategies for improved heterologous expression of laccase in Pichia pastoris. Biotechnol Bioeng. 2002;79:438-49.

45. Jahic M, Wallberg F, Bollok M, Garcia P, Enfors S-O: Temperature limited fed-batch technique for control of proteolysis in Pichia pastoris bioreactor cultures. Microbial Cell Factories 2003, 2

46. Marx H, Mecklenbräuker A, Gasser B, Sauer M, Mattanovich D. Directed gene copy number amplification in Pichia pastoris by vector integration into the ribosomal DNA locus. FEMS Yeast Res. 2010;9:1260-70.

47. Fukusaki El, Nishikawa T, Kato K, Shinmyo A, Hemmi H, Nishino T, Kobayashi A. Introduction of the archaebacterial geranylgeranyl pyrophosphate synthase gene into Chlamydomonas reinhardtii chloroplast. J Biosci Bioeng. 2003;95:283-7.

48. Wang CW, Oh MK, Liao JC. Directed evolution of metabolically engineered Escherichia coli for carotenoid production. Biotechnol Prog. 2000;16:922-6.

49. Yan L, Ding XM, Xue ZL, Hu LX, Zhang NJ, Zhou W, Yang JW, Qian C, Chen MH, Zhang ZZ. The change of the state of cell membrane can enhance the synthesis of menaquinone in Escherichia coli. World J Microbiol Biotechnol. 2017;33:52.

50. Wang H, Liu H, Wang L, Zhao G, Tang H, Sun X, Ni W, Yang Q, Wang $P$, Zheng Z. Improvement of menaquinone-7 production by Bacillus subtilis natto in a novel residue-free medium by increasing the redox potential. Appl Microbiol Biotechnol. 2019;103:7519-35.

51. Ma Y, McClure DD, Somerville MV, Proschogo NW, Dehghani F, Kavanagh JM, Coleman NV. Metabolic engineering of the MEP pathway in Bacillus subtilis for increased biosynthesis of menaquinone-7. ACS Synth Biol. 2019;8:1620-30.

\section{Publisher's Note}

Springer Nature remains neutral with regard to jurisdictional claims in published maps and institutional affiliations. 